\title{
Density-thermal dependence of sedimentary associations calls to reinterpreting detailed gravity surveys
}

\author{
Vagif G. Gadirov ${ }^{1}$, Lev V. Eppelbaum ${ }^{2,}{ }^{\star}$ \\ ${ }^{1}$ OilGas Scientific Research Project Institute, Baku, Azerbaijan \\ ${ }^{2}$ Tel Aviv University, Faculty of Exact Sciences, Department of Geosciences, Tel Aviv, Israel
}

\author{
Article history \\ Received September 27, 2014; accepted November 19, 2014. \\ Subject classification: \\ Temperature, Density, Subvertical zone, Gravity anomaly.
}

\begin{abstract}
The modern gravimetric equipment allows to register very small effects of gravity field changes and can be applied solving different geological, geophysical and environmental problems. However, sometimes insuffcient calculation of various kinds of geological noise complicates effective application of detailed gravity field analysis. One of such factors is the temperature regime over and outside different buried objects of investigation. In this paper temperature changes in a subvertical zone over a hydrocarbon deposit and outside its contour are analyzed. The integrated density change and corresponding gravity effects are calculated for the Muradkhanly oil deposit situated within the south-east part of the Middle Kura Depression (central Azerbaijan). Calculation of these effects on the basis of density-temperature data correlation analysis could significantly improve the microgravity field examination over the hydrocarbon deposits. The similar correction procedure may be applied also over underground water horizons and some environmental targets.
\end{abstract}

\section{Introduction}

Development of a new modern gravimetric and variometric (gradientometric) equipment (permitting registering earlier inaccessible small anomalies and improving the observation methodology) and creation of new methodologies for gravity data processing and interpretation have triggered an increase of microgravity methodology application in environmental and economic minerals geophysics [Eppelbaum 2011]. However many kinds of noise complicate the precise gravity field analysis (the detailed block-scheme of disturbances arising in detailed gravity surveys is presented in Figure 1). One of such disturbances is the densitythermal dependence (see "Dependence on other physical parameters" in Figure 1).

Let us consider the density-thermal effect on example of gravity field examination over a hydrocarbon deposit. The rocks composing sections of hydrocarbon deposits (HD) are characterized as a rule by inhomogeneity and variety of petrophysical characteristics. It is known that in HD different physical-chemical processes exist which frequently generate subvertical zones with distinct physical characteristics over HD [Berezkin et al. 1978, Berezkin et al. 1982, Gadirov 2009, Gadirov and Eppelbaum 2012]. Such zones usually outline vertical migration of fluid flows from the deposits.

Registered geophysical anomalies (including gravity and magnetic effects) over hydrocarbon structures are explained by physical properties (for instance, density and magnetization) change and specific distribution of petrophysical properties which were traced for many hundreds of meters over HD occurrences.

Analysis of numerous geological-geophysical data testifies to relation of some geophysical anomalies with HD; these anomalies did not observe over the "empty" structures. Various researchers note those inhomogeneous zones over HD distinct from the surrounding media by their magnetic, density, thermal and other physical characteristics [Berezkin et al. 1978, Seifullin 1980, Foote 1996, Maksymchuk et al. 2012].

A presence of specific columnar (subvertical) zone with lowered density over HD is a reason of majority of observed negative gravity effects. We must note that existence of subvertical zone over HD has been discussing from the 70-s of the 20th century till the present, and morphology of these zones is explained from different points of view [e.g., Berezkin et al. 1982, Roslov et al. 2009, Meger'ya 2011]. Some similar effects (but more weak) are observed in hydrogeological and geoenvironmental investigations [e.g., Somerton 1992, Singhal and Gupta 2010, Eppelbaum et al. 2014].

Porosity and density of HD collectors do not change, but hydrocarbons extrude water from the 


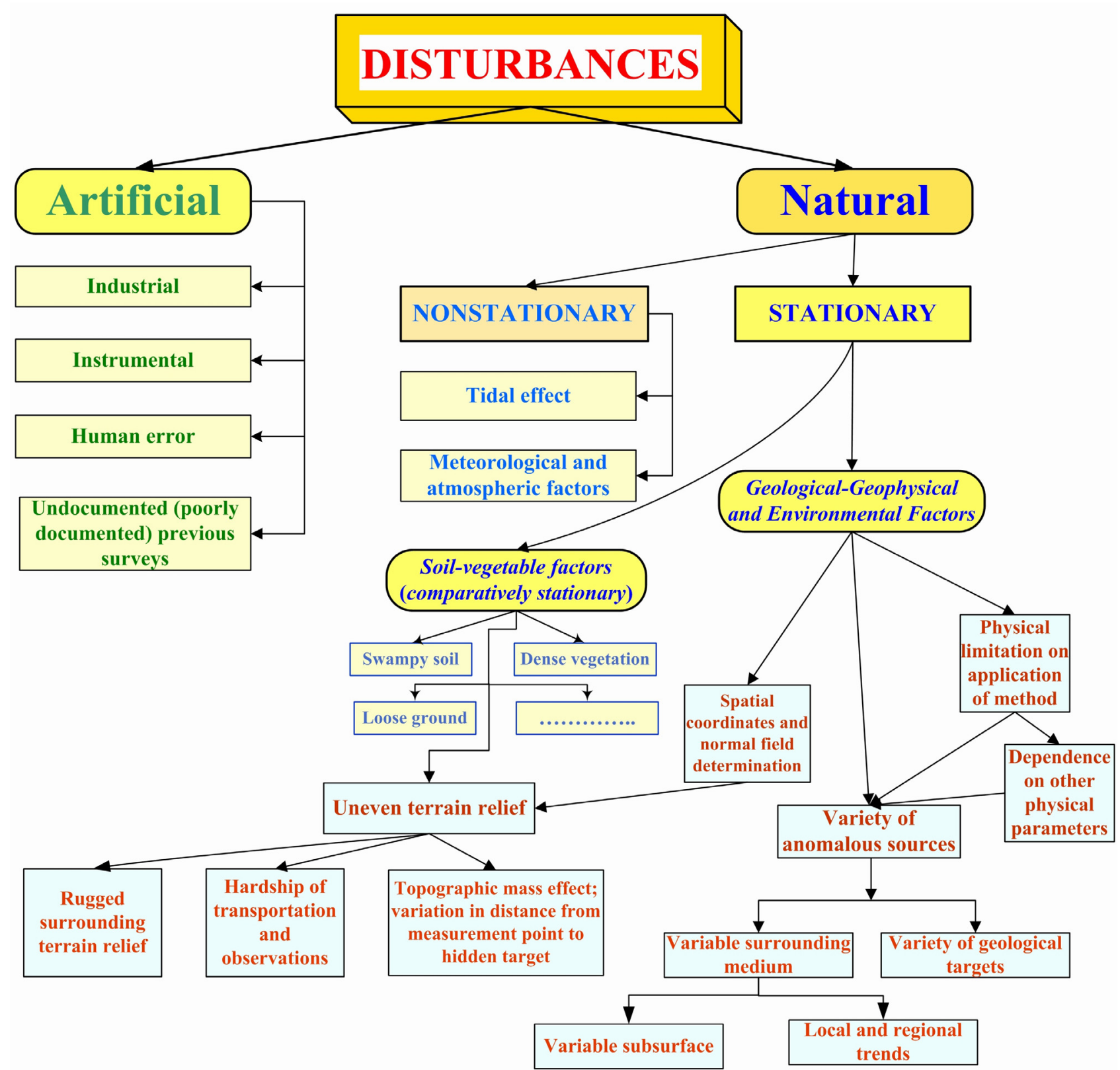

Figure 1. Noise affecting microgravity investigations (modified and enlarged after Eppelbaum, [2010]).

porous space that leads to density decrease in the subvertical zone over HD. At the same time, quantitative estimation of corresponding physical properties changes in this zone has not been conducted. Some parameters of magnetic susceptibility and temperature changing in subvertical zone over HD were analyzed in [Gadirov 2009, Gadirov and Eppelbaum 2012]. In this investigation we suggest to utilize temperature data for estimation of rock density changing in subvertical zone over HD.

This investigation was carried out for the example of the Muradkhanly deposit (description of this deposit was given in Eppelbaum and Khesin [2012]) situated within the south-east part of the Middle Kura Depression, on the western slope of Sabirabad-Kurdamir zone of highs (Azerbaijan). This deposit was discovered in
1971 when firstly in Azerbaijan oil reserves were found in volcanogenic associations of Upper Jurassic (in interval of 3798-3761 m). This discovering served a foundation for carrying out wide-ranging drilling in this area. In these boreholes numerous measurements of temperature have been performed. The temperature data were carefully studied and the results are employed in this investigation.

\section{Analysis of temperature effects over hydrocarbon deposit}

For studying thermal characteristics of geological associations in the Mutadkhanly and adjacent areas are constructed graphs of temperature changing versus depth both within deposits and without their contours (Figures $2 \mathrm{a}$ and $2 \mathrm{~b}$, respectively). Table 1 shows some 


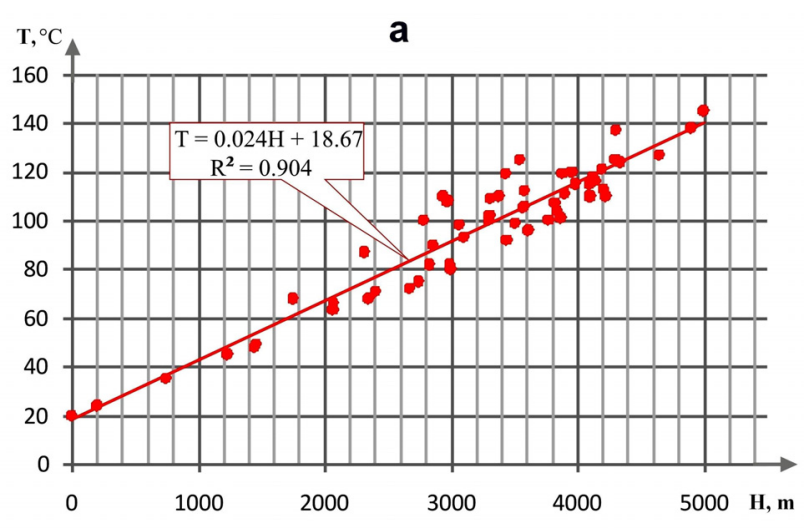

b

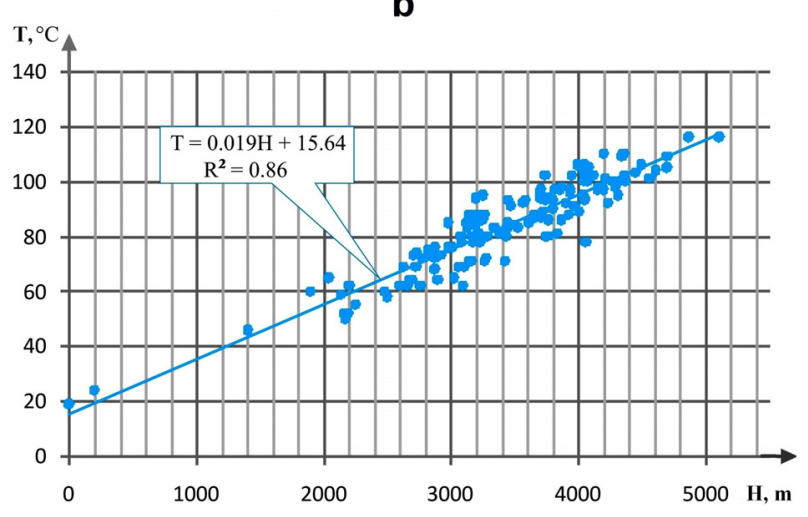

Figure 2. Graphs of the temperature dependence on the depth in oil deposit Muradkhanly: (a) inside the deposit contour, (b) outside the deposit contour. $H$ is depth, and $R$ is the correlation coefficient. key lithological, density, porosity and thermal data for the Muradkhanly area. Thermal values as a whole increase with depth due to geothermal gradient, but some quasi-chaotic distribution was also revealed in the area. By other words, in some boreholes at one depth various temperatures were observed, and the same temperatures were observed at different depths. Nevertheless linear relationships of temperature versus depth with sufficiently high coefficients of correlation $R$ were obtained ( $R$ for the graph presented Figure 2a is computed as 0.951 and for the graph shown in Figure $2 b$ - as 0.927). Comparison of the obtained regressions indicates that temperature values versus depth over HD increase more rapidly than without the deposit contour. With depth increase the difference between temperatures observed within the deposit contour and without it is also increase (Figure 3).

It is known that temperature increase causes volume expansion of physical bodies (including geological associations) that leads to decreasing their density [Eppelbaum et al. 2014]. However, values of rock thermal expansion is so small that to detect it in HD areas practically is not possible. Deep well sections in the $\mathrm{Mu}-$ radkhanly area indicate that oil deposit was discovered at the depth about $3000 \mathrm{~m}$ in the arched uplift, and at the depth of $4000 \mathrm{~m}$ in the western continuation of the

\begin{tabular}{|c|c|c|c|c|c|c|c|c|}
\hline $\begin{array}{l}\text { Geological } \\
\text { age }\end{array}$ & Lithology & $\begin{array}{l}\text { Depth, } \\
\text { m }\end{array}$ & $\begin{array}{l}\text { Vertical } \\
\text { thickness, } \\
\text { m }\end{array}$ & $\begin{array}{c}\text { Average } \\
\text { density, } \\
\mathrm{kg} / \mathrm{m}^{3}\end{array}$ & $\begin{array}{c}\text { Porosity } \\
\text { n, } \%\end{array}$ & $\begin{array}{l}\text { Temperature } \\
\text { increment } \\
\text { in contour } \\
\text { zone of } \\
\text { deposit } \Delta t \text {, } \\
{ }^{\circ} \mathrm{C}\end{array}$ & $\begin{array}{c}\text { Coefficient } \\
\text { of volume } \\
\text { temperature } \\
\text { expansion } \\
\left(\beta \cdot 10^{-5}, 1 /{ }^{\circ} \mathrm{C}\right)^{*}\end{array}$ & $\begin{array}{c}\text { Decreasing } \\
\text { rock density } \\
\text { over deposit } \\
\text { calculated } \\
\text { using Eq. (5), } \\
\Delta \sigma, \mathrm{kg} / \mathrm{m}^{3}\end{array}$ \\
\hline$Q$ & $\begin{array}{l}\text { sandstones, } \\
\text { clays, sand }\end{array}$ & $0-400$ & 400 & 2050 & 22 & 5.03 & 2.9 & 0.72 \\
\hline $\begin{array}{l}\text { Q1, } \\
N_{2}^{2}\end{array}$ & $\begin{array}{l}\text { sandstones, } \\
\text { sands, } \\
\text { siltstones, } \\
\text { limestone }\end{array}$ & $400-2000$ & $\begin{array}{c}1200 \\
500\end{array}$ & 2130 & 25 & 13.03 & 2.9 & 2.53 \\
\hline $\begin{array}{c}\text { pay } \\
\text { section } \\
N_{2}^{1}\end{array}$ & $\begin{array}{c}\text { clays, } \\
\text { sandstones, } \\
\text { siltstones }\end{array}$ & $2000-2200$ & 200 & 2235 & 18 & 14.03 & 2.7 & 2.18 \\
\hline $\begin{array}{l}N_{1} \\
N_{1}^{2}\end{array}$ & $\begin{array}{l}\text { sandstones, } \\
\text { clays }\end{array}$ & $2200-2750$ & $\begin{array}{c}500 \\
50\end{array}$ & 2210 & 15.9 & 17.03 & 2.9 & 2.52 \\
\hline $\mathrm{P}_{3}+N_{1}^{1}$ & $\begin{array}{l}\text { limestone, } \\
\text { clays }\end{array}$ & $2750-3400$ & 650 & 2300 & 16.2 & 20.03 & 2.7 & 2.94 \\
\hline \multirow[t]{2}{*}{$\mathrm{P}_{2}$} & $\begin{array}{c}\text { clays, } \\
\text { calcareous } \\
\text { sandstones }\end{array}$ & $3400-3900$ & 500 & 2340 & 11.2 & 23.03 & 2.9 & 2.89 \\
\hline & & & & & & & & $\begin{array}{c}\Delta \sigma_{\text {aver }}= \\
2.45 \mathrm{~kg} / \mathrm{m}^{3}\end{array}$ \\
\hline
\end{tabular}

Table 1. Some geological-petrophysical characteristics of rocks composing section of the Muradkhanly deposit. $* \beta_{w}=59 \cdot 10^{-5}, 1 /{ }^{\circ} \mathrm{C}$ $\left(\beta_{w}\right.$ is the volume thermal expansion of water). 


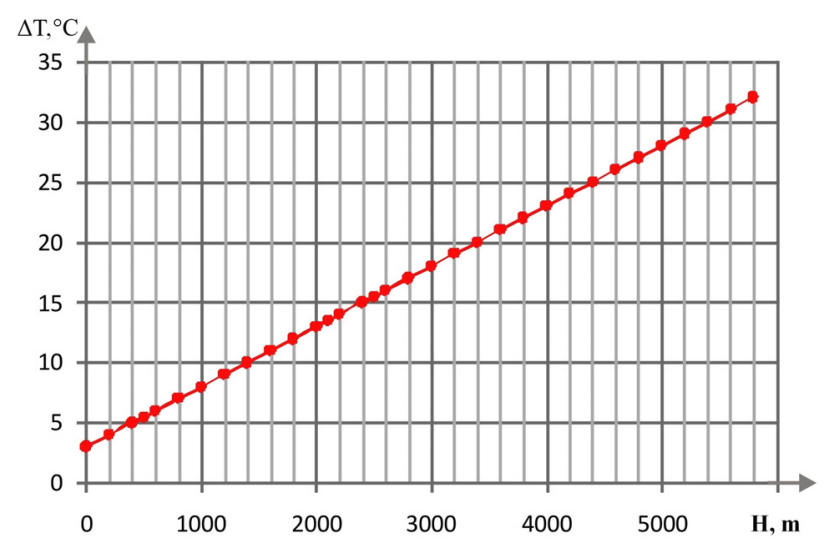

Figure 3. Graph of changing of temperature versus depth within the contour of Muradkhanly deposit.

structure. The temperature difference at the depth of $4000 \mathrm{~m}$ between the arched uplift and western part consists of about $23^{\circ}$ (Figure 3). Applying Equation (1) (see below) and accepting value of volume thermal expansion $\beta$ as $2.9 \cdot 10^{-5} 1 /{ }^{\circ} \mathrm{C}$, and density as $2340 \mathrm{~kg} / \mathrm{m}^{3}$ (see Table 1) we obtain $\Delta \sigma \approx 2 \mathrm{~kg} / \mathrm{m}^{3}$. It will be very hard to detect such rock density changes by any geophysical method in the central part of the deposit concerning to the peripheral part (even in the case of their identical stratigraphy and lithology).

However, presence of fluids in geological sections sharply changes the physical pattern. For instance, volume thermal expansion of water under temperature of $50-80^{\circ} \mathrm{C}\left(\beta_{w}=59 \cdot 10^{-5} 1 /{ }^{\circ} \mathrm{C}\right)$ almost in 20 times exceeds the volume thermal expansion of sandstone. It is known that water in geological section fills porous space in the majority of geological rocks. Consequently we cannot consider volume thermal expansion of water and mineral skeleton separately since water expansion in the porous rock space will create corresponding pressure to the solid shell of the rocks. In this case porous pressure will increase and probably a zone of abnormally high layer pressure will be generated. Analysis of pressures in boreholes at Muradkhanly area has shown that there is not a clear relationship between the pressure distribution and HD location in this area. The abovementioned facts indicate that temperature change in the studied areas is accompanied by volume and density change by constant mass.

A relationship between the density and temperature is well-known [e.g., Somerton 1992]:

$$
\sigma_{t}=\sigma_{0} \frac{1}{1+\beta t},
$$

where $\sigma_{0}$ and $\sigma_{t}$ are the targets densities at temperatures 0 and $t^{\circ} \mathrm{C}$, respectively, and $\beta$ is the coefficient of volume thermal expansion of targets.

Bodies with density $\sigma_{t_{1}}$ at temperature $t_{2}$ will have density $\sigma_{t_{2}}$ :

$$
\sigma_{t_{2}} \approx \sigma_{t_{1}} \frac{1}{1+\beta\left(t_{2}-t_{1}\right)}
$$

Based on Equation (2) we can determine the difference in body densities depending on temperature changes:

$$
\begin{gathered}
\sigma_{t_{1}}-\sigma_{t_{2}}=\sigma_{t_{1}}-\sigma_{t_{1}} \frac{1}{1+\beta\left(t_{2}-t_{1}\right)}=\frac{\beta\left(t_{2}-t_{1}\right)}{1+\beta\left(t_{2}-t_{1}\right)} \cdot \sigma_{t_{1}} \\
\text { or } \\
\qquad \sigma_{\Delta t}=\frac{\beta \Delta t}{1+\beta \Delta t} \cdot \sigma_{t_{1}}
\end{gathered}
$$

where $\Delta \sigma_{\Delta t}$ is target density change by corresponding temperature change for $\Delta t$ interval, and $\sigma_{t_{1}}$ is the target density at temperature $t_{1}$.

Equation (4) can be applied for a homogenous body. Geological rocks occurring in in the depth interval of $0-10 \mathrm{~km}$ as a rule consist of solid part, liquid (water) and gaseous phase filling the rock porous space. Taking into account that contribution of gaseous phase is usually negligible, let us present changes of solid phase density and water, respectively as:

$$
\Delta \sigma_{\Delta t}^{r}=\frac{\beta_{r} \Delta t}{1+\beta_{r} \Delta t} \cdot \sigma_{t_{1}}^{r}
$$

and

$$
\Delta \sigma_{\Delta t}^{w}=\frac{\beta_{w} \Delta t}{1+\beta_{w} \Delta t} \cdot \sigma_{t_{1}}^{w}
$$

where $\Delta \sigma_{\Delta t}^{r}$ and $\Delta \sigma_{\Delta t}^{w}$ are the changings (increments) of rock and water density, respectively depending on temperature changing $\Delta t ; \beta_{r}$ and $\beta_{w}$ are the coefficients of volume thermal expansion of rock and water, respectively.

The volume occupied by liquid (water) may be estimated from use coefficient of porosity $n$. Then solid phase will occupy $(1-n)$ part of the volume unit. Total density change of solid skeleton and water may be presented as:

$$
\Delta \sigma_{\Delta t}=\Delta \sigma_{\Delta t}^{r}(1-n)+\Delta \sigma_{\Delta t}^{w} n
$$

After substituting Equations (5) and (6) to Equation (7) we receive:

$$
\Delta \sigma_{\Delta t}=\frac{\left[\sigma_{t_{1}}^{r} \beta_{r}(1-n)+\sigma_{t_{1}}^{w} \beta_{w} n\right] \Delta t}{1+\left(\beta_{r}+\beta_{w}\right) \Delta t} .
$$

Equation (8) enables us to calculate density decrease over HD relative to it peripheral part (outside the deposit contour). We must note that denominator in Equation (8) is close to one and we can neglect it.

For estimation of the temperature effect the well- 


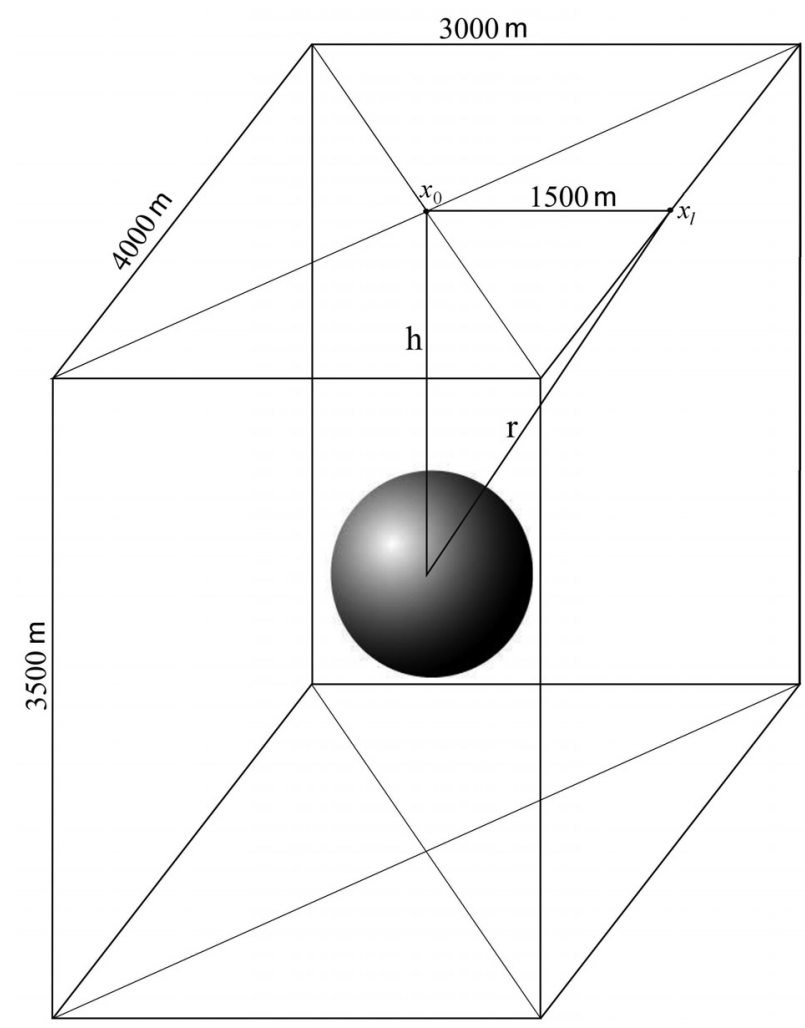

Figure 4. Model for computation of gravity effect of "deficient" mass in the subvertical zon over deposit.

studied Muradkhanly deposit (Middle Kura Depression, Azerbaijan) was selected. This deposit was comprehensively investigated by numerous drilling operations and geophysical methods and may be considered as polygon for testing different methodologies.

The temperature data processed for the Muradkhanly area enabled us to estimate the density change in this area. Application of Equation (8) indicates that decreasing rock density in the contour part of the deposit relative to the peripheral part averagely consists of $2.45 \mathrm{~kg} / \mathrm{m}^{3}$. Practically the density decrease exceeds this value since besides thermal volume expansion, extending liquid phase also produces some rock expansion.

\section{Calculation of gravity effect caused by thermal regime peculiarities}

How this nonsignificant rock density decrease could influence to amplitude and behavior of gravity anomaly? For this aim it is necessary to compute the direct calculation of deficit mass over the oil pool affecting the gravity field.

We will develop a model of gravity deficit mass over HD in the subvertical zone with the example of the Muradkhanly oil deposit. As was aforementioned the oil deposit in this area was discovered at the depth of $3000 \mathrm{~m}$ on the arch and consisted of more than $4000 \mathrm{~m}$ on the wings. In the oil-bearing part of the geological structure with a dimension $3 \times 4 \mathrm{~km}$ the total volume of the deposits consists approximately $42 \cdot 10^{9} \mathrm{~m}^{3}$. In this case the nonsignificant density decrease $\left(-2.45 \mathrm{~kg} / \mathrm{m}^{3}\right)$ could cause to deficit of mass in this area as several tens of million tons. In this concrete example the deficit of mass is:

$\mathrm{m}=v \sigma=42 \cdot 10^{9} \cdot 2.45 \mathrm{~kg}=102.9 \cdot 10^{9} \mathrm{~kg}=$ $=102.9 \cdot 10^{6}$ tons $\approx 10^{8}$ tons.

Which gravity effect may produce such a mass? We will conduct some simple calculations. Let's assume that the "missing" mass is concentrated in the middle of the geological section as a sphere (Figure 4). Then the gravity effect from this target may be calculated using known expression:

$$
\Delta g=G M \frac{h}{r^{3}},
$$

where $G$ is the universal gravity constant, $M$ is the mass, $h$ is the depth of sphere occurrence, and $r$ is the distance from the sphere center to the point of gravity effect calculation.

Let us compute the gravity effect in points $x_{0}$ and $x_{l}$ disposed directly over the sphere and over the boundary of deposit, respectively:

$$
\left\{\begin{array}{l}
\Delta g=G M \frac{1}{h^{2}}=0.22 \mathrm{mGal}\left(1 \mathrm{mGal}=10^{-5} \mathrm{~m} / \mathrm{s}^{2}\right) \\
\Delta g_{x_{l}\left(x_{l}=1500 \mathrm{~m}\right)}=G M \frac{h}{r^{3}}=0.098 \mathrm{mGal}
\end{array}\right\} .
$$

The difference $\Delta x$ between points $x_{0}$ and $x_{1}$ consists of 0.122 milliGal $\left(1\right.$ milliGal $\left.=10^{-5} \mathrm{~m} / \mathrm{s}^{2}\right)$. In fact, taking into account that our calculation was applied to "missing mass", we must use this value with an inverse sign: -0.122 milliGal. The distribution of gravity effect due to the geothermal phenomenon between the $x_{0}$ and $x_{l}\left(x_{l}\right.$ here was assumed as $\left.2000 \mathrm{~m}\right)$ is presented in Figure 5 . Today when we speak about microGal $(1 \mu \mathrm{Gal}=$ $10^{-8} \mathrm{~m} / \mathrm{s}^{2}$ ) anomalies [Eppelbaum 2011], the aforementioned value (122 microGal) may have an important role in gravity field examination in oil and gas bearing areas.

Performed 3D modeling of gravity field have shown that for real situations the estimations of gravity effects decrease in 1.25-1.4 times, but and for these cases the gravity effects are significant and considerably exceed the errors of the Bouguer gravity determination in field conditions. Calculation of temperature effect will enable to receive more exact gravity anomalies and to avoid some mistakes by geophysical data analysis not only in hydrocarbon geophysics, but also in hydrogeological, environmental (e.g., karst localization) and other investigations. 


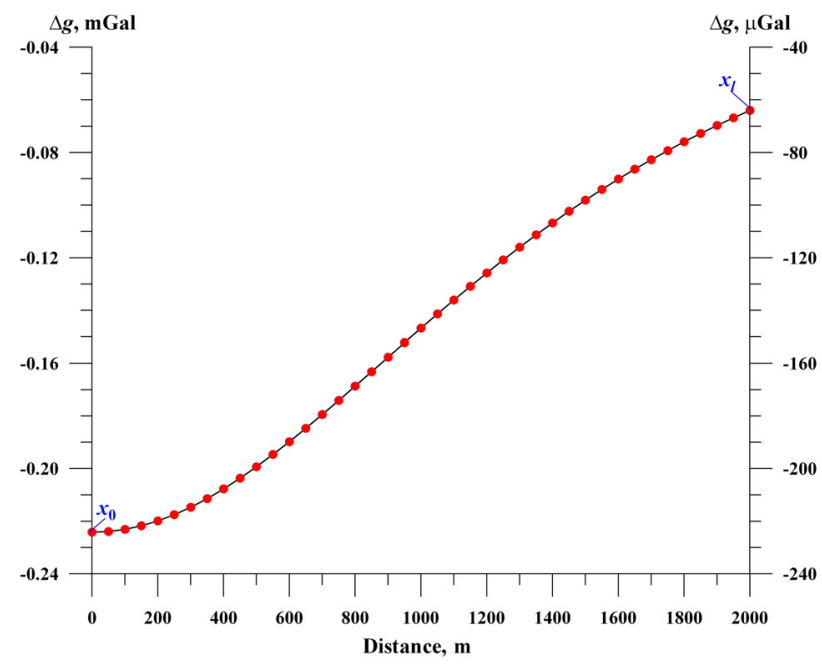

Figure 5. A distribution of gravity effect between the $x_{0}$ and $x_{l}(l=$ $2000 \mathrm{~m}$ )

\section{Conclusions}

It was shown increasing temperature over hydrocarbon deposit only for several degrees causes small decreasing of this zone rocks comparting with it peripheral part (about $2.45 \mathrm{~kg} / \mathrm{m}^{3}$ ). However, even such nonsignificant density changing by sufficient vertical zone thickness (several thousand meters) over HD creates considerable gravity effect - several tenth parts of milliGal that can play a significant role for detection and localization of hydrocarbon deposits including inefficient and deep-seating ones. Thus, the detailed gravity analysis over the hydrocarbon structures, as well as in hydrogeological and environmental studies should be accompanied by thermal data examination.

Acknowledgements. The authors would like to thank two anonymous reviewers who thoroughly reviewed the manuscript, and which valuable suggestions were very helpful in preparing this paper.

\section{References}

Berezkin, V.M., M.A. Kirichek and A.A. Kunarev (1978). Application of Geophysical Methods for Direct searching Oil and Gas Deposits, Nedra, Moscow (in Russian).

Berezkin, V.M., G.A. Bannikova and I.S. Mazurova (1982). Revealing ring subvertical inhomogeneties by by gravity data by oil and gas searching, Applied Geophysics, 103, 100-104 (in Russian).

Eppelbaum, L.V. (2010). Archaeological geophysics in Israel: Past, Present and Future, Advances of Geosciences, 24, 45-68.

Eppelbaum, L.V. (2011). Review of environmental and geological microgravity applications and feasibility of their implementation at archaeological sites in Israel, International Journal of Geophysics, ID 927080 , 1-9; doi:10.1155/2011/927080.

Eppelbaum, L.V., and B.E. Khesin (2012). Geophysical
Studies in the Caucasus, Springer.

Eppelbaum, L.V., I.M. Kutasov and A.N. Pilchin (2014). Applied Geothermics, Springer.

Foote, R.S. (1996). Relationship of near-surface magnetic anomalies to oil and gas producing areas, AAPG Memoir 66: Hydrocarbon Migration and its Near Surface Expression, 111-126.

Gadirov, V.G. (2009). Results of application of gravitymagnetic surveys for prognosis oil\&gas deposits in the Kura Depression of Azerbaijan, Geophysics (Moscow), 2, 51-56 (in Russian).

Gadirov, V.G., and L.V. Eppelbaum (2012). Detailed gravity, magnetics successful in exploring Azerbaijan onshore areas, Oil and Gas Journal, Nov. 5, 110 (11), 60-73.

Maksymchuk, V., R. Kuderavets, I. Chobotok and V. Tymoschuk (2012). High-resulution surveys for oil and gas fields searching in NW part of the Carpathian fore deep, Trans. of 2nd Intern. Conf. Alpine-Petrol 2012, Krakow-Poland, 83-84.

Meger'ya, V.M. (2011). Searching and prospecting of hydrocarbon deposits associated with geosoliton degassing of the Earth on the basis seismic imaging, Geophysics (Moscow), 1, 67-74 (in Russian).

Roslov, Yu.V., N.N. Efimova, A.N. Kremlev and A.D. Pavlenkin (2009). Seismic features of fluid flow and associated with it deposits, Geophysics (Moscow), 2, 26-30 (in Russian).

Seifullin, R.C. (1980) Relationship of thermal and magnetic anomalies over hydrocarbon deposits with natural electric fields, Oil\&gas Geology and Geophysics, 8, 42-43 (in Russian).

Singhal, B.B.S., and R.P. Gupta (2010). Applied Hydrogeology of Fractured Rocks, Springer.

Somerton, W.H. (1992) Thermal Properties and Temperature-Related Behaviour of Rock-Fluid Systems, Elsevier.

${ }^{\star}$ Corresponding author: Lev V. Eppelbaum,

Tel Aviv University, Faculty of Exact Sciences, Department of Geosciences, Tel Aviv, Israel; email: levap@post.tau.ac.il.

C 2015 by the Istituto Nazionale di Geofisica e Vulcanologia. All rights reserved. 